\title{
Study the Effect of Corrosion on the Pipes of Oil Well Production
}

\author{
Dr. Ramzy. S. Hamied, Dr. Mohammad. A. Alhassan, Dr. Mayssaa. A. AL-Bidry
}

Petroleum Technology Department / University of Technology

\section{$\underline{\text { Abstract }}$}

Corrosion costs of the oil industry are billions of dollars in a year. Corrosion affects every aspect of exploration and production of oil, from offshore rigs to casing and transporting the crude oil to refinery or exporting terminal. This study aims to investigate the effect of sulfur content on the corrosion of carbon steel and composite material (polyester/fiberglass) pipes used in well production.

In the present work three specimens of pipes from (Al - Nasiriyah oil field, Al - Daura refinery, and composite material) are prepared in the center of the training and workshop in university of technology with $(3$, and $5 \mathrm{~mm})$ thickness and $(30 \mathrm{~mm})$ diameter which immersed in different types of Iraqi crude oil field (East - Baghdad, Al - Nasiriyah, and Al - Rumaila field) in different times (0, 14, 28, 42, and 56 day). Physical properties (viscosity, density, API grade, specific gravity (sp.gr), sulfur $\%$, sediment $\%$, and water \%) of three types of Iraqi crude oil are tested in lab of petroleum technology department. Also study specimens of pipes by microscope to knowing the effect of sulfur $\%$ on these specimens.

The results showed that when increasing duration of immersed pipes and sulfur content in crude oil increased the rate of corrosion, and the composite material pipe gives the best result compared with the other two specimens pipes used because they didn't influenced by corrosion when immersed in Iraqi crude oil. Also, it was noted that the diffusion coefficient decreased in composite pipe compared with the other pipes.

Key word: Corrosion, Petroleum Industry, Oil Well, Crude Oil.

\section{Introduction}

The Petroleum industry contains a wide variety of corrosive environments. Some of these are unique to this industry. Thus it is convenient to group all these environments together. Corrosion problems occur in the petroleum industry in at least three general areas: (1) production, (2) transportation and storage, and (3) refinery operations [1,2].

The sulfur compounds found universally in crude oil cause many handling and manufacturing difficulties. In sour crude oils, sulfur, in the form of hydrogen sulfide, polysulfide's, mercaptans, 
thiophenes and elemental state presents difficulties in handling, transportation and storage because of the extreme toxicity and corrosiveness of sulfur contaminants. The costs of lost time, the replacement of materials of construction, and the constant personnel involvement in corrosion control are essential, if not controlled can be fatal [3,4]. The costs attributed to corrosion damages of all kinds have been estimated to be of the order of 3\% to $5 \%$ of industrialized countries' gross national product [5].

Popoola L. T, et al, 2013 [5], study comprehensive review of corrosion problems during oil and gas production and its mitigation. It is recommended that consultations with process, operations, materials, and corrosion engineers are necessary in the fitness of things to save billions of dollars wasted on corrosion in the oil and gas industries. Song et al, 2004 [6], Corrosion of carbon steel is a significant problem in the oil \& gas production and transportation systems, which causes significant economic loss. As a result of corrosion, rupture of the pipe wall frequently causes failure of petroleum and gas pipelines.

Corrosion is a major concern with steel piping, particularly in geothermal applications. A distinct disadvantage in using steel pipe is that the buried pipe is also subject to external corrosion [7].

Composite material (polyester/fiberglass) pipes corrosion control resists caused by $\mathrm{CO}_{2}, \mathrm{H}_{2} \mathrm{~S}$ and saltwater. Requires no protective coating. Reduced line pipe installation cost, light and easy to handle. Less personnel and equipment needed during installation. Improved flow capacity, smoother interior pipe surface increases efficiency and resists scale/paraffin build-up [8].

The aims of this research to study the effect of sulfur content on the corrosion of carbon steel and composite material (polyester/fiberglass) pipes used in well production by using different Iraqi crude oil.

\section{EXPERIMENTAL WORK}

\section{Materials:}

\section{Iraqi Crude oil properties:}

There are many types of crude oil, the important characteristics to classify the density (heavy crude, medium heavy, and light crude), viscosity (the degree to which the crude oil resists flow) and Sulfur content. This study has focused on the heavy and light crude oil acted three pipes specimens .A good example of Iraqi heavy crude comes from East Baghdad field and light crude from Al Nasiriyah, and the medium type, Al - Rumaila field.

The physical properties of three types Iraqi crude oil (API, density, viscosity, sulfur $\%, \ldots .$. ) are tested in the basic crude oil laboratory in petroleum technology department / university of 
technology as shown in table (1).

\section{Pipes specimens:}

This part focuses the effect of sulfur content in the Iraqi crude oil (East - Baghdad, Al Nasiriyah, and Al - Rumaila field) on corrosion of three specimens of pipes from (Al - Nasiriyah oil field, Al - Daura refinery, and composite material).

The preparing pipes sample using different mechanical operations were conducted in the center of the training and workshop in university of technology (band saw, hydraulic press, C.N.C milling machine, and grinding machine), the specimens are circles with (3, and $5 \mathrm{~mm})$ thickness and (30 $\mathrm{mm}$ ) diameter and the face of this specimens are polished.

Table (1) Physical Properties of Iraqi Crude Oil

\begin{tabular}{|c|c|c|c|}
\hline Properties & East Baghdad & Nasiryah & Rumaila field \\
\hline API & 20 & 29.72 & 24 \\
\hline Viscosity & $3.09 \mathrm{cp}\left(17.8^{\circ} \mathrm{C}\right)$ & $0.05 \mathrm{cp}\left(17.8^{\circ} \mathrm{C}\right)$ & $0.13 \mathrm{cp}\left(17.8^{\circ} \mathrm{C}\right)$ \\
\hline Sp.gr & 0.935 & 0.8777 & 0.915 \\
\hline Density & 0.935 & 0.8777 & 0.915 \\
\hline Sulfur $\%$ & $0.72 \%$ & $0.39 \%$ & $0.32 \%$ \\
\hline Sediment & $2 \%$ & - & 0.43 \\
\hline Shear stress & $3.79 \mathrm{D} / \mathrm{cml}$ & $0.07 \mathrm{D} / \mathrm{cml}$ & $0.04 \mathrm{D} / \mathrm{cml}$ \\
\hline Shear rate & $122.311 / \mathrm{sec}$ & $122.31 / \mathrm{sec}$ & $122.31 / \mathrm{sec}$ \\
\hline Water content & - & $1.6 \%$ & - \\
\hline
\end{tabular}




\section{Calculation}

\section{Diffusion Coefficient}

Diffusion coefficient calculation by using Fick's second law in order to predicts how diffusion causes the concentration to change with time (unstable state), by applying the equation (1) [8].

$D=\pi\left(K . b / 4 \cdot M_{X}\right)^{2}[9]$

\section{Where:}

D: diffusion coefficient $\left(\mathrm{m}^{2} / \mathrm{sec}\right)$.

$\boldsymbol{K}$ : The slope of the linear portion of the curve between profit weights with the square root of time.

$M_{x}$ : Water content at the current arrival Saturation condition (highest value for mass gain) (g).

$\boldsymbol{b}$ : Thickness of pipe specimens $(\mathrm{mm})$.

- Calculation of weight gain \% for pipe specimens immersed in Iraqi crude oil using in this work by applying equation (2):

Weight Gain \% $=M_{1}-M_{0} / M_{0} \quad[9]$

\section{Where:}

$\boldsymbol{M}_{1}$ : mass of pipe specimens before immersion in crude oil $(g)$.

$\boldsymbol{M}_{0}$ : mass of pipe specimens after immersion in crude oil $(\mathrm{g})$.

\section{Tests of Pipes Specimens}

This part of study include testing three types of pipes specimens in each type of Iraqi crude oil by immersing this specimens in baker (cylindrical glass) with $50 \mathrm{ml}$ of crude oil (East - Baghdad, Al Nasiriyah, and Al - Rumaila field) for time duration (0, 14, 28, 42, and 56 day). The specimens withdrawn from the backer dried and put in glass descanter for $24 \mathrm{hr}$ then taking the weight of these specimens and put again in the backer, repeat this procedure for all time duration in order to calculate rate of corrosion (weight loss method). As shown in below figure: 


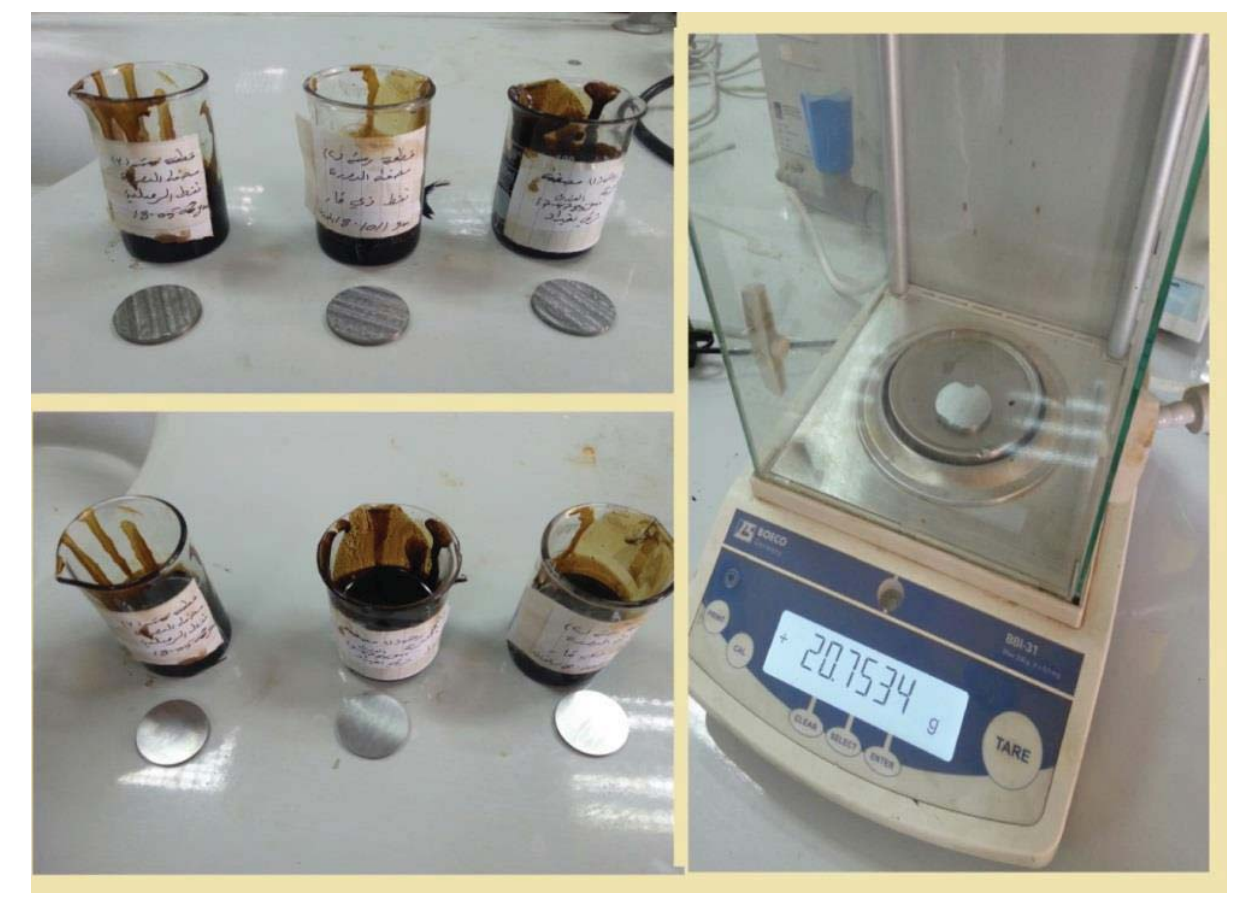

\section{Study Pipes Specimens by Microscope}

Study the effect of sulfur \% on pipes specimens for three different Iraqi crude oil using microstructures optical microscopy (reflect microscope, model BX51MRF, Olympus, Japan), in order to show the corrosion was happen on the surface only for three pipes specimens or the water soluble iron naphthenate produced by chemical reaction between naphthenic and ferrous sulfides with the flow of the heavy oil which further impelled the local corrosion of the stainless steel.

\section{$\underline{\text { Results and discussion }}$}

\section{Rate of corrosion \%}

The effect of sulfur content in Iraqi crude oil (East-Baghdad, Al- Nasiriyah, and Al- Rumaila field) test on three types of pipes specimens (Al-Nasiriyah oil field, Al-Daura refinery, and composite material) in order to estimate rate of corrosion $\%$, are shown in figures $(1,2$, and 3$)$ : 


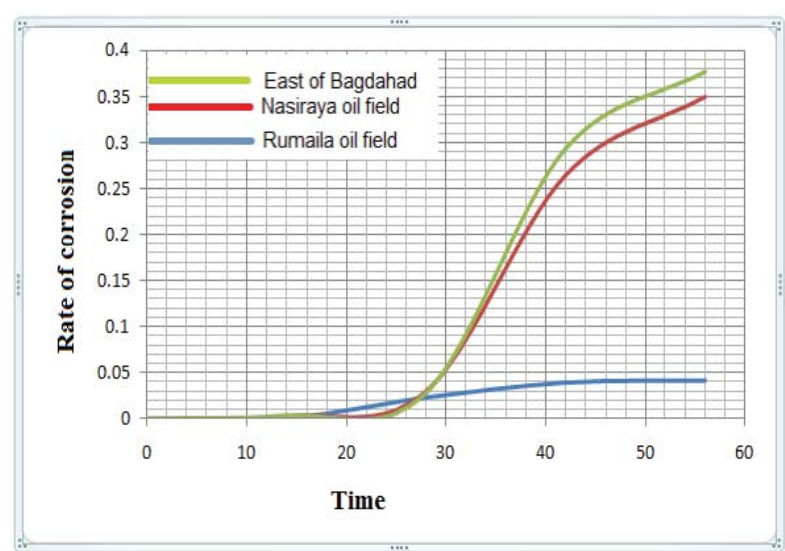

Fig. (1) Rate of corrosion \% vs Time, for Al- Dura pipe

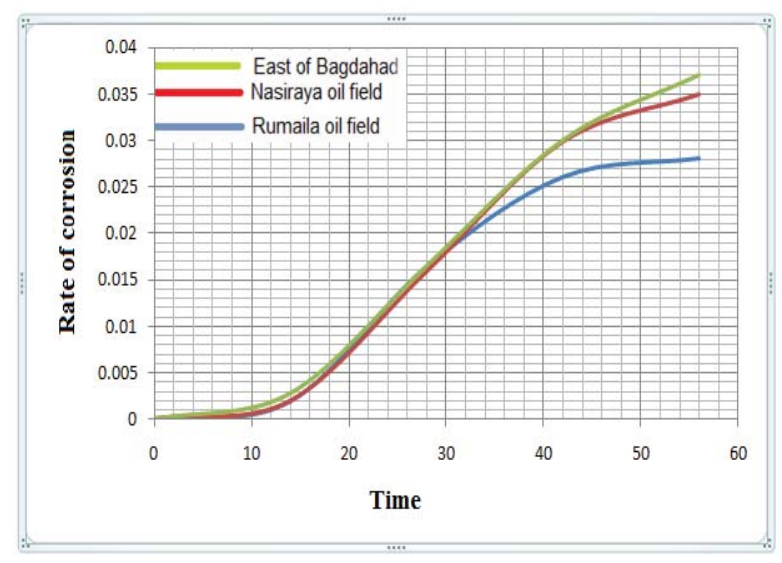

Fig. (2) Rate of corrosion \% vs Time, for Al - Nasiriyah pipe

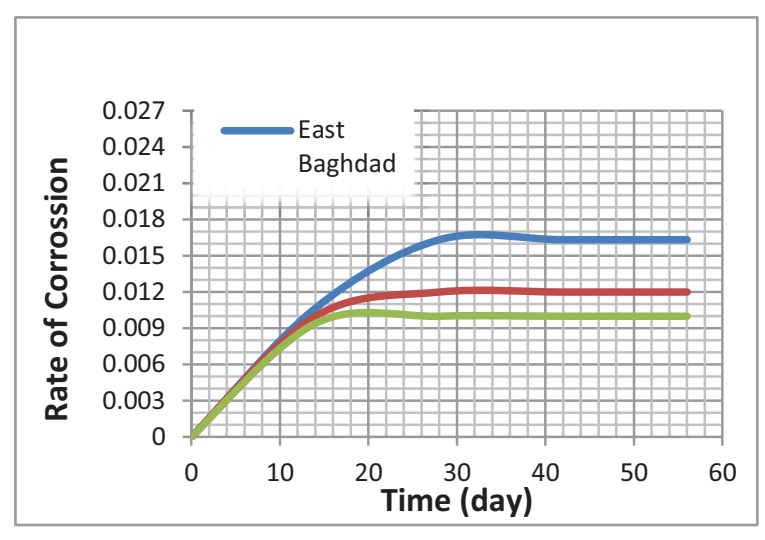

Fig (3) Rate of Corrosion \% vs Time, for Composite Materials Pipe

The results illustrates in figure (1, and 2 ) shows that the rate of corrosion $\%$ increase with increasing sulfur content in crude oil and immersed duration time for pipes specimens. Since the maximum rate of corrosion \% reach to $0.377 \%$ for (East - Baghdad), $0.3492 \%$ for (Al - Nasiriyah), and $0.0412 \%$ for (Al - Rumaila ) crude oil field (Al - Dura pipe), while $0.037 \%$ for (East - Baghdad), 0.035\% for (Al - Nasiriyah), and $0.028 \%$ for (Al - Rumaila ) crude oil field (Al - Nasiriyah pipe), which means that the sulfur content is the main source of corrosion in pipelines compare with additional factors such as (sediment content and water content.....).

It's clearly that the result from figure (3) illustrate maximum rate of corrosion for composite material pipe equal to $0.01633 \%$ for (East - Baghdad), $0.012 \%$ for (Al - Nasiriyah), and $0.01 \%$ for (Al Rumaila) crude oil field, which is shown the lowest value compare with the other pipes using. The primary incentive for using composite material piping is to avoid corrosion problems commonly 
experienced by carbon steels in oil field corrosive fluids. The typical applications are production gathering and produced water injection or disposal piping systems. The production fluids may contain high water content with associated acidic gases. The produced water may be very saline. In such fluids, bare carbon steels often experience high corrosion rates and frequent leaks [10].

\section{Diffusion Coefficient Parameters}

The diffusion coefficient can be calculated by applying equation (1) after plot graphical relationship between the weight gain percent versus square root of time in order to find the inclination value. Table (2) show diffusion coefficient values for three types of Iraqi crude oil to each pipe specimens.

Table (2) Diffusion coefficient of Iraqi crude oils for each pipe specimens

\begin{tabular}{|c|c|c|c|}
\hline \multirow{2}{*}{ Pipe types } & \multicolumn{3}{|c|}{ Diffusion coefficient $D\left(m^{2} / \mathrm{sec}\right)$} \\
\hline & East Baghdad field & Nasiriyah field & Rumaila field \\
\hline Al - Nasiriyah & $0.872 * 10^{-9}$ & $1.362 * 10^{-9}$ & $4.906^{*} 10^{-10}$ \\
\hline Al - Dura & $3.141 * 10^{-8}$ & $4.906^{*} 10^{-8}$ & $7.065 * 10^{-10}$ \\
\hline Composite material & $2.233 * 10^{-11}$ & $1.963 * 10^{-11}$ & $1.250 * 10^{-11}$ \\
\hline
\end{tabular}

The result from table (2) showed that the highest value of diffusion coefficient for East Baghdad oil field which characterized as heavy crude oil and higher sulfur content which are considered increased rate of corrosion compare with other two types. The composite material pipe show that lower value because that rate of corrosion for three types of crude oil very low compare with the other pipe specimens

\section{Study corrosion by Microscope}

The microstructures by optical microscopy clearly show the corroded structure of three pipes specimens with products of corrosion over it as shown in below figure. It's clearly illustrate that the form of corrosion seems to be localized corrosion on the surface of the sample between parallel lamellae (ribbons) picture (1, and 2), and some irregular corrosion which extended to the matrix picture (3), There were some pits and some ulcer red spots picture (4). The corrosion product was covered on the specimen surface only, so there was not effect after removing the corrosion product picture (5). The corrosion rate increase with increasing sulfur and water contain. The sulfur corrosion increased because the effect of large cathode and small anode [11 and 12]

The corrosion product increase with East Baghdad crude oil. The corrosion rate increase with 


\section{No.19}

\section{(JPR\&S)}

increase sulfur and water contain. The area that effect by corrosion with Al - Rumaila crude oil was very small because the sulfur content was low. It can be seen that there is good agreement between the high corrosion rates and high concentration of sulfur and water contain.

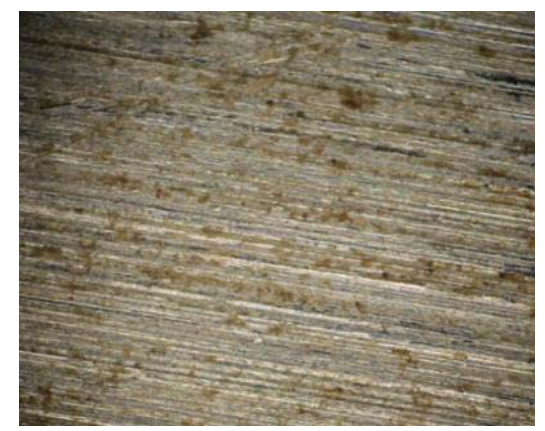

(1)

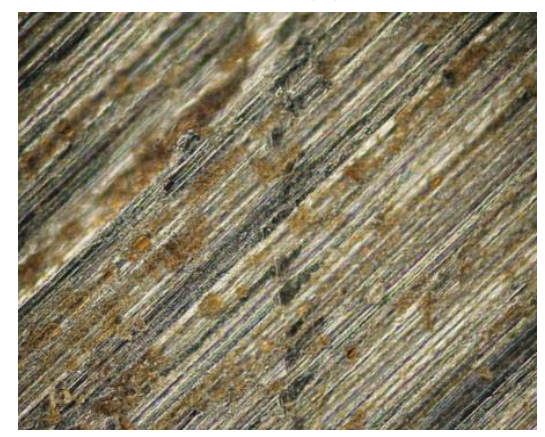

(3)

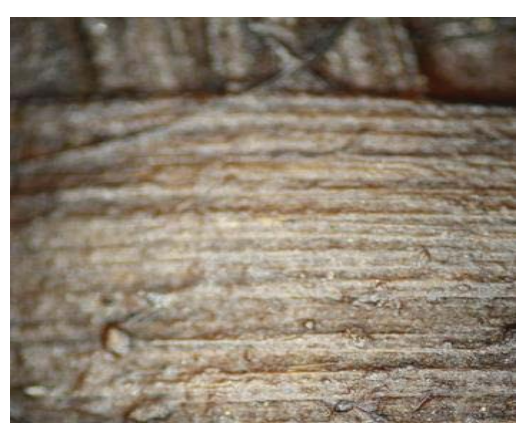

(2)

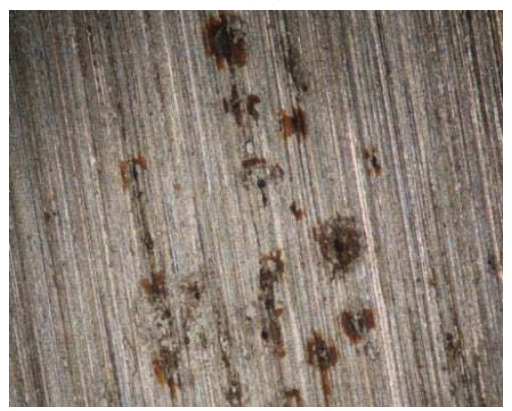

(4)

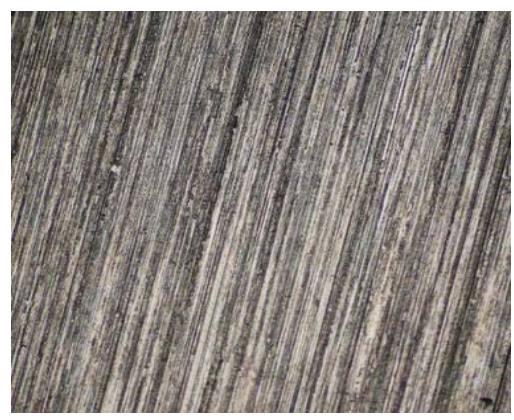

(5)

Fig (4) Microscopic optical structure for three pipe specimens. (1) Nasiriyah oil on Al-Dura pip, (2) East-Baghdad oil on Composite pipe, (3, and 4) East-Baghdad oil on Nasiriyah and AlDura pipes, (5) Al-Dura pipe after polishing. 


\section{No.19}

Journal of Petroleum Research \& Studies

(JPR\&S)

\section{Conclusions}

The results shows that when increasing sulfur content in crude oil will increase corrosion $\%$ in pipe for carbon - steel type also the thickness of pipe inversely effect on corrosion \%, since the result of (East - Baghdad) crude oil for tow type pipes (Al - Dura, and Al - Nasiraya) maximum corrosion \% reach to $0.38 \%$ and $0.037 \%$ respectively. It's clearly that the results for composite material pipe corrosion \% low value since it reach maximum to $0.0163 \%$ for three types of Iraqi crude oil using in this study, because the good characteristics of this pipe compare with carbon steel pipe.

It's important to mention her that the diffusion coefficient decreased in composite pipe compared with the other pipes (carbon - steel). The microstructures by optical microscopy clearly show the corroded structure with products of corrosion over it the corrosion product was covered on the specimen surface only, so there was not effect after removing the corrosion product. Finally we concluded that this type of pipe using as RTRP (reinforced thermosetting resin pipe) or FRP (fiberglass reinforced plastic) used in most industries requiring corrosion resistance pipe. 


\section{References}

1. Prabh.S.S, Rathish. R.J., R.Dorothy, Brindha.G., M.Pandiarajan, Al-Hashem.A., and, Rajendran.S., "Corrossion Problems in Petroleum Industry and their Solution", Eur.Chem.Bull, 3(3), pp 300-307, 2014.

2. http:// corrosion - malaysiapetroleum. blogspot.in/2008/06/corrosion - in petroleumindustry.html.

3. "Production and Processing of High Sulfur Crude and Associated Gas", NTNU (Det Skapende Universitet) TPG4510 Petroleum Production Specialization Project, Darkhan. Duissenov, Nov, 2012.

4. www.google.co.in/search? $\mathrm{q}=$ corrosion + in + petroleum + industry\&oq=corrosion + in + petroleum +industry\&aqs $=$ chrome..69i57j015.8972j0j8\&sourceid $=$ chrome\&espv=210\&es_sm=93\& ie $=$ UTF- 8 .

5. Popoola. L. T., Grema.A. S., Latinwo.G. K., B.Gutti and, Balogun.A. S.," Corrosion problems during oil and gas production and its mitigation", Popoola et al. International Journal of Industrial Chemistry, 4:35, 2013.

6. Raffertry.K.,’Piping”, Geo - Heat Center, GHCBulletin, March 1998.

7. “Fiber Glass Systems", National Oil Well Varco USA (www.fiberglasssystem.com), 2005.

8. Apicella. A., et al., “Composite”, Vol. 13, No. 4, P.P (406 - 410), 1982.

9. Musa. B.H., "Study the propagation properties and thermal conductivity of a UPE / NBR thread supported by a ceramic powder", Diyala. Journal for Science, Vol (6), No (4), October 2010.

10. Lee. G.L., "High Pressure Hot Fluid Oil Field Fiberglass Pipeunes”, International Pipeline Conference - Volume 2, IPC1996-1876, P.P (711-715), ASME 1996.

11. Wang. X., Wei. Y., Show. C., Shi. Y., Xue. W., Zhu. J., "Study on corrosion behavior of the 304 stainless steel in the heavy oil with high salt, high sulfur and high acid value", Applied Mechanics and Materials Online. ISSN: 1662-7482, Vol. 252, pp (271-275), 2013.

12.Paul. S., Pattanayak. A. and, Guchhait. S.K., "Corrosion Behavior of Carbon Steel in Synthetically Produced Oil Field Seawater", international Journal of Metals Volume 2014, Article ID 628505, pages (11), 2014. 